\title{
Anja Amend-Traut, Anette Baumann, Stephan Wendehorst, Steffen Wunderlich (dir.), Die höchsten Reichsgerichte als mediales Ereignis
}

München : Oldenbourg (Bibliothek altes Reich), 2012, 234 p., 39,80€

Falk Bretschneider

\section{OpenEdition}

\section{Journals}

Édition électronique

URL : http://journals.openedition.org/ifha/7700

DOI : 10.4000/ifha. 7700

ISSN : 2198-8943

\section{Éditeur}

IFRA - Institut franco-allemand (sciences historiques et sociales)

\section{Référence électronique}

Falk Bretschneider, «Anja Amend-Traut, Anette Baumann, Stephan Wendehorst, Steffen Wunderlich (dir.), Die höchsten Reichsgerichte als mediales Ereignis », Revue de l'IFHA [En ligne], Date de recension, mis en ligne le 13 décembre 2013, consulté le 22 septembre 2020. URL : http:// journals.openedition.org/ifha/7700; DOI : https://doi.org/10.4000/ifha.7700

Ce document a été généré automatiquement le 22 septembre 2020

(CIFHA 


\section{Anja Amend-Traut, Anette Baumann, Stephan Wendehorst, Steffen Wunderlich (dir.), Die höchsten Reichsgerichte als mediales Ereignis}

München : Oldenbourg (Bibliothek altes Reich), 2012, 234 p., 39,80€

Falk Bretschneider

Résultat du $8^{\mathrm{e}}$ colloque, organisé en 2009, du « réseau juridiction impériale » (Netzwerk Reichsgerichtsbarkeit) - un groupe de chercheurs qui s'efforce depuis plusieurs années et à travers un nombre désormais important de publications d'élargir nos connaissances sur les modes de fonctionnement de la justice du Saint-Empire - le présent ouvrage est paru dans une collection qui se donne pour objectif de rassembler des recherches interdisciplinaires sur l'ancien Reich, en mettant l'accent notamment sur des approches récentes telle que l'histoire de la communication. Le livre se propose justement d'analyser le travail des tribunaux suprêmes (Reichshofrat ou Conseil aulique impérial et Reichskammergericht ou Tribunal de la Chambre impériale) comme des actes symboliques et performatifs. Autrement dit, l'activité de la juridiction impériale n'est pas étudiée ici sous l'angle de ses résultats, les sentences rendues par les juges, mais sous celui de la médialité de la fabrication d'un droit revêtu de l'autorité de l'Empereur et de l'Empire. À travers une mise en scène des tribunaux eux-mêmes, mais davantage encore par le biais des stratégies communicationnelles de leurs usagers, le droit impérial et les institutions qui l'incarnaient deviendraient ainsi un "événement médiatique» (mediales Ereignis) dont les dix contributions du recueil (outre l'introduction signée par S. Wunderlich) poursuivent les traces sous différents aspects.

A. Deutsch étudie ainsi l'image de la juridiction suprême dans quelques chroniques de l'époque moderne dont les descriptions permettent, selon lui, un accès privilégié à la perception «subjective» des tribunaux impériaux par les contemporains. M. von 
Loewenich met en valeur les huit représentations connues de l'audience (reproduites dans le texte) comme un moment essentiel de visualisation du Tribunal de la Chambre impériale, moment inscrit dans une stratégie de légitimation rendue nécessaire par la distance géographique envers la cour impériale. La dernière inspection de ce tribunal, entreprise entre 1767 et 1776, fait l'objet de l'article d'A. Denzler qui insiste sur la contradiction apparente entre le fort écho médiatique qu'a suscité cette inspection dans de nombreuses publications et le secret qui, au moins en principe, était censé l'entourer. Les agents du Conseil aulique impérial, représentants des plaignants et idéalement pourvus d'un fort capital social leur offrant un accès direct aux principaux acteurs du tribunal, jouent un rôle fondamental, souligné par le texte de T. Dorfner, dans la communication souvent informelle entre les parties du procès et le tribunal luimême. D. Petry analyse les procès menés devant le Conseil aulique par les Villes d'Empire au xviIIe siècle comme des "événements médiatiques» d'une portée suprarégionale (p.114), en insistant d'une part sur l'activité des commissions locales qui, par leur présence sur place et contrairement au tribunal viennois, longtemps presque invisible, veillaient activement à leur propre mise en scène, et d'autre part sur les stratégies médiatiques des parties ressemblant véritablement à des «formes primitives d'actions de relation publique» (p.131). M. Bähr, examinant les comptes rendus d'interrogatoires de témoins devant la Chambre impériale, s'intéresse à la coexistence entre le jargon hautement spécialisé des juristes et le langage, et le savoir, de l'homme du commun. Les procès menés entre 1521 et 1555 devant la Chambre et ayant pour objet des conflits confessionnels interprétés comme une atteinte à la paix publique (Landfriedensbruch) sont étudiés par T. Branz. B. Schneiderse consacre aux conflits internes de la famille des Fugger portés devant les deux tribunaux de l'Empire, en analysant notamment leurs correspondances comme un instrument stratégique destiné à influencer le cours du procès. Le transfert des principes du droit impérial vers les juridictions territoriales est analysé par S.A. Stodolkowitz à partir du cas de la cour suprême d'appel de Celle (fondée en 1711), en montrant par exemple l'« osmose personnelle » (p. 207) entre les juristes actifs aux deux niveaux, mais surtout le rôle essentiel de la littérature juridique pour une pratique largement homogène du droit dans l'Empire et ses composants. Enfin, le texte d'I. Czeguhnse penche sur la mise en scène monumentale de la justice royale après la reconquête de Grenade par la couronne espagnole au xvie siècle, exauçant ainsi un souhait émis par S. Wunderlich dans son introduction, celui d'une comparaison plus poussée entre la situation dans l'Allemagne moderne et d'autres pays européens davantage centralisés.

L'ensemble des contributions se caractérise par une diversité assez importante et produite, nous semble-t-il, par l'absence d'un travail notionnel plus rigoureux. Si quelques articles traitent effectivement de la représentation des deux tribunaux impériaux dans des images ou des écrits imprimés et donc, si l'on veut, de leur médialité, d'autres parlent de sujets apparemment sans rapport direct avec le sujet général de l'ouvrage. La notion d'« événement médiatique " reste finalement assez floue et difficilement saisissable, ce qui ne signifie pas pour autant qu'il n'y a aucun profit à tirer de cette lecture. Au contraire, la plupart des contributions proposent des perspectives intéressantes, il leur manque cependant une orientation théorique commune. Si, rendu friand par les acquis récents de l'«histoire culturelle du politique ", le lecteur s'attend aux premiers résultats cohérents d'une histoire culturelle du droit (impérial), il lui faudra attendre encore un peu. 
INDEX

Index chronologique : Frühe Neuzeit

Thèmes : Politische Geschichte

\section{AUTEUR}

\section{FALK BRETSCHNEIDER}

École des Hautes Études en Sciences Sociales, Paris 